\title{
Peter Pernthaler
}

\section{Allgemeine Staatslehre und Verfassungslehre}

Springer-Verlag, Wien/New York, 1986, XXV + 477 S., DM 98,-

Die $P$. Saladin und in ihm der Schweizer Staatsrechtslehre zugeeignete Verbindung der Allgemeinen Staatslehre "als typologisch beschreibende Wissenschaft realer Staaten mit einer wertenden Verfassungslehre eines konkreten Staatstypus: des demokratischen Verfassungsstaates" (Vorwort), die der Innsbrucker Ordinarius vorlegt, will "Verständnis, kritische Wertung und persönliche Verantwortung für den Verfassungsstaat als die derzeitige Existenzbedingung politischer Humanität wecken" (ebd.). Dabei negiert der Autor nicht etwa "Staatlichkeit" als unabdingbaren Bestandteil freiheitlicher und sozialgerechter Gesellschaftsordnung (12), sieht freilich das "Ganze" des Staats als in der Geschichte stehendes Sein, als Prozeß (32) und insistiert durchweg auf dem praktischen Problem einer geeigneten Staatsorganisation: Wie weit dürfen Schranken die Staatsgewalt in ihrer Wirksamkeit und Durchsetzungskraft begrenzen, ohne dadurch deren ordnende Funktion entscheidend zu beeinträchtigen und in ihrer eigentlichen Bedeutung für die Gesellschaft zu entwerten (147 f., $156 \mathrm{f}$.)?

Nach den heutigen Bedingungen der "Industriegesellschaft" - und der Existenz des Menschen in ihr - ließen sich hier (typologische) Grundaufgaben des Staates ermitteln, die seine institutionelle Struktur im ganzen prägten: die Sicherung des Rechtsfriedens, die Herstellung einer funktionsfähigen Wirtschafts- und Sozialordnung, die Gewährleistung der kulturellen Entwicklung und - zuletzt, aber nicht zumindest - der Schutz der Umwelt (95). Die heute mehr als je gebotene, wenigstens teilweise Abkopplung des Menschen von zentraler Steuerung, Versorgung und Normierung, wie sie parallel mit einer Reaktivierung seiner Selbstgestaltungsfähigkeit und Solidarität erfolgen müsse, sei nur auf der Grundlage gewisser äußerer rechtlicher und organisatorischer Bedingungen möglich; "innere Befreiung" basiere auf Föderalismus, Dezentralisation, Autonomie und Grundrechtswirksamkeit (145).

Angesichts dieses Grundthemas nimmt es nicht wunder, wenn der Abschluß (und Höhepunkt) des "Kurzlehrbuchs" (?) Abschnitte über "Naturrecht - Widerstandsrecht Menschenrechte" (348 ff.) sowie "Föderalismus, Bundesstaat, Autonomie" (404 ff.) bilden. Aus völkerrechtlicher Warte mögen hier vornehmlich die freilich recht knappen Passagen zu Verbrechen gegen die Menschlichkeit (357, 361 - man vermißt den aktuellen Fall Barbie) und zum Verhältnis von völkerrechtlichen Friedenspflichten und Widerstandsrecht (373 ff.) interessieren. Nur zu wahr ist P.s Resumé, kein Menschenrechtskatalog, kein Verfassungsschutz und kein Ombudsman(n) vermöge wirksamen Grundrechtsschutz ohne die Kraft des Bewußtseins der Freiheit herzustellen (403). Uberaus optimistisch tönt hingegen das Hohe Lied des ("integralen", 410) Föderalismus (415 ff.), es mündet letztlich in die Feststellung, ein Dualismus von nächster Heimat (auch im geistigen Sinne) und universeller Friedensordnung, die eine Offenheit für die Vielfalt der Kulturen und Völker bedeutet, sei das eigentliche Erbe Europas (459).

Wiewohl primär Staats-Lehre und daher mit Erscheinungen wie (Staats-) Volk, Staats- 
gewalt, -organisation und -funktionen beschäftigt (35 ff., $111 \mathrm{ff}$., $158 \mathrm{ff}$., $201 \mathrm{ff}$.), schenkt $P$. genügend Aufmerksamkeit auch den Beziehungen von Staat und Gesellschaft (62 ff., 80 ff.), ja, ein gewichtiges Kapitel behandelt die organisierte Gesellschaft als demokratische Infrastruktur (302 ff.), wobei zum einen die politischen Parteien, hernach Verbände und Wirtschaftsunternehmen in ihrer öffentlichen Bedeutung erörtert werden. Während "informale" Aktivitäten der Sache nach durchaus Beachtung finden (335 ff., 390), räumt P. den "multinationalen" Unternehmen nur wenige Zeilen (344) - und keinen Platz im Sachverzeichnis! - ein. Insgesamt freilich erhalten Wirtschaftsleben und -politik ihre wohl angemessene Erwähnung, nicht zuletzt auch die "Zentralnotenbank" $(13,126,187,232,258,332)$ - auch ihr bleibt aber die Aufnahme in den Findex versagt, wie des weiteren dem Asylrecht $(394,397)$. An entstellenden Druckfehlern fiel mir nur Art. 19 III (statt: IV, 296) auf; etwas ärgerlich stimmt freilich, wenn die am Beginn jedes $\S$ aufgelistete Literatur nicht nur für Studenten oftmals zu pauschal bezeichnet ist und/ oder sich in aufeinanderfolgenden Gliederungspunkten unterscheidungslos wiederholt. Der demokratische Verfassungsstaat hat in P.s Werk eine gelungene Würdigung seiner Höhen wie der (Un-) Tiefen erfahren. Dem Poe-Leser (s. 169) sei der Nachsatz verstattet: "Der Mann, der verbraucht worden war" (so die Úbersetzung von Hans Wollschläger) ist weniger "Held des technischen Zeitalters" als Ritter von der traurigen Gestalt (s. Zumbach, E.A. Poe, 1986, 377).

Ludwig Gramlich

Philip Kunig/Wolfgang Benedek/Costa R. Mahalu

Regional Protection of Human Rights by International Law: The Emerging African System

Verfassung und Recht in Ubersee, Beiheft 12, 1985, Nomos Verlagsgesellschaft, BadenBaden, 156 Seiten, DM 29,-

Die drei Verfasser: Kunig (Universität Hamburg, jetzt Heidelberg), Benedek (Universität Graz) und Mahalu (Universität Dar es Salaam) haben sich eine interessante Aufgabe gestellt, die man mit vergleichender Darstellung des regionalen Menschenrechtsschutzes umschreiben könnte. Diese regionale Zwischenebene der Menschenrechte, die auch in Europa und Amerika von steigender Bedeutung ist, besteht seit einiger Zeit auch in Afrika und könnte hier noch von größerer Bedeutung sein, da die Defizite in einzelnen Staaten größer sind als in beiden anderen eben erwähnten Rechtsbereichen.

Mahalu, dessen Monographie 'Public International Law and Shipping Practices: The East African Aspirations' 1984 in Deutschland veröffentlicht wurde, eröffnet die Darstellung mit dem Beitrag: "Africa and Human Rights". Im ersten Abschnitt wird das Problem der Menschenrechte und der afrikanischen Gesellschaft (African Communities) historisch aufgezeigt, im zweiten Teil (S. 6 ff.) wendet sich der Verfasser der postkolonia- 